\title{
Capitalist Spirit and the Markets: Why Income Inequality Matters
}

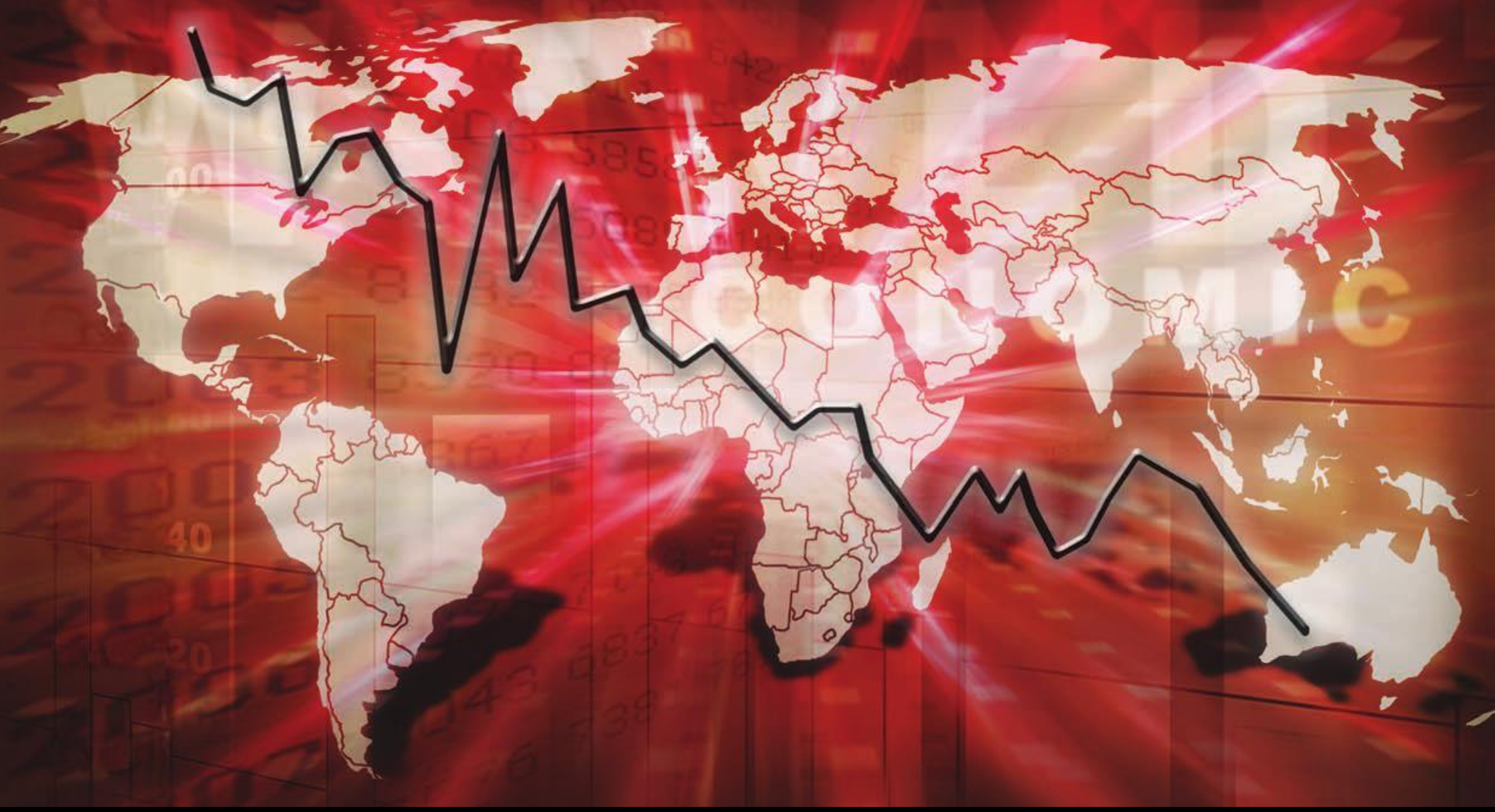

Aristotelis Boukouras, University of Leicester 


\title{
Capitalist Spirit and the Markets: Why Income Inequality Matters
}

\author{
Aristotelis Boukouras*
}

October 30, 2016

\begin{abstract}
I develop a simple static general equilibrium model with capitalist-spirit preferences and prices set by firm owners (entrepreneurs). The model's pure symmetric Nash equilibria differ markedly from the canonical model: (i) A positive output gap and unemployment may emerge in equilibrium, despite the absence of price rigidities or information asymmetries. (ii) Income and wealth inequality affect equilibrium prices and employment. (iii) The model generates ambiguous comparative statics. Specifically, an increase in inequality of either type may reduce employment and increase the output gap of the economy, while productivity reductions may have the opposite effect. As a result, minimum wage policies may increase employment. These results provide some justification for a number of arguments used in public debates.
\end{abstract}

Keywords: capitalist spirit, general equilibrium, income distribution, income inequality, minimum wage, output gap, unemployment, wealth distribution, wealth inequality

JEL Classification: D31, D63, E24, E25

${ }^{*}$ University of Leicester, AC206, Astely Clarke Building, University Road 1, LE1 7RH, Leicester, UK, email: Aris.Boukouras@le.ac.uk 


\section{Introduction}

Many western economies, including US, UK and the European Union, suffer from weak growth, low inflation and extremely low, or even negative, interest rates in the aftermath of the Great Recession. Summers (2014a, 2014b) calls this phenomenon "secular stagnation" and many economists agree that it is a result of weak aggregate demand (Summers, 2014a). However, New-Keynesian models, which are the mainstream demand-side models used by academic economists, have difficulty explaining the persistence of demand weakness on the basis of price rigidities. Almost eight years after the Great Recession prices and wages should have converged to their long-run equilibrium value, especially since empirical evidence suggests that they adjust at least as frequently as once a year (Klenow and Malin, 2010; Nakamura and Steinsson, 2013). Moreover, income and wealth inequality, a prominent feature of recent public debates, play little role in the standard Keynesian framework. While non-academic economists often postulate that the increase in income inequality in the past two decades is a factor behind the weakness of aggregate demand (The Economist, 2014; Wolf, 2014), academic economists do not validate this argument on a theoretical level. On the contrary, most of the models in this area tend to attribute a positive role to increasing inequalities (Aghion et al., 1999).

The purpose of this paper is twofold. First, to present a simple theoretical model where demand-side considerations matter for the determination of the equilibrium without the presence of any price or wage rigidities. Second, to demonstrate how wealth and income inequality are non-neutral if the economy is demand-constrained, meaning that equilibrium employment and prices are implicit functions of the respective distributions of income and wealth. To achieve these purposes, I develop a simple static general equilibrium model with two goods and two classes of citizens, workers and entrepreneurs. The first good is a standard commodity good that is produced by entrepreneurs' firms through the workers' (inelastic) labor supply, while the second good is the means of trade, a measure of wealth and status, and in fixed supply. A natural interpretation of the second good is money or gold, but it could also be any other good in fixed supply (e.g. land or classical artwork). The key assumptions are that citizens derive utility from holding it and that it is in fixed supply. I allow prices and wages to be determined endogenously by entrepreneurs under an environment of perfect labor competition and a flexible modelling of commodity competition that encompasses both perfect competition and local monopolies as special cases, and I analyse the pure symmetric Nash 
equilibria of the economy.

The first main result that comes out of the analysis is that pure symmetric Nash equilibria exist, but they do not necessarily entail full employment. To the contrary, an equilibrium may feature a positive output gap and unemployment. The rest of the results comes out of comparative statics exercises, which demonstrate that the reaction of equilibrium employment to economic shocks depends critically on whether the economy is demand or supply constrained. If the economy is supply constrained, that is if there is no output gap, then the conventional results hold: wealth and income inequality are neutral and productivity increases raise output. But if the economy is demand constrained, conventional wisdom may fail to hold, i.e. increases in the inequality of either type may reduce employment and output, and so is the case with productivity increases. Moreover, minimum-wage policies which force entrepreneurs to pay higher wages may increase equilibrium employment.

From a theoretical perspective, these results are born by the interaction between the demand for the good in fixed supply and the equilibrium concept. The fact that one of the goods in the economy is in fixed supply means that, if citizens derive sufficiently high marginal utility from holding it, then their demand from the producible goods is limited and so is the demand of labor. This generates a tendency for equilibrium unemployment to arise endogenously. However, if one were to solve the model using the methodology of competitive equilibrium, this tendency, by the equilibrium's very definition, would not materialise. Thus, the use of Nash equilibrium removes the ad-hoc market-clearing condition and allows for the endogenous emergence of a positive output gap.

The comparative statics results, then, follow from the differences in the marginal utility of consumption of the status good between workers and entrepreneurs, which affect the composition of the aggregate demand for the producible good. If the marginal utility of the status good is sufficiently higher for entrepreneurs than workers then income and wealth redistributions which favor the former weaken aggregate demand and, depending on the sensitivity of prices to demand changes, may decrease aggregate employment and output. The other side of the coin is that policies, which favor workers, such as minimum-wage policies, may strengthen aggregate demand and increase equilibrium employment. Similarly, increases in productivity have an ambiguous effect on output when the economy is demand constrained, since they increase entrepreneurs' profits and demand for the commodity, while they decrease labor demand and workers' commodity demand. The overall effect depends on the differences in marginal utilities 
between the two classes and on the degree of commodity competition. While the model is too simple to provide a comprehensive policy analysis, it is easy to generalise and expand, and it demonstrates in a clear fashion the breath of results that can be obtained from an alternative modelling approach to demand-side models.

In terms of literature, the obvious point of comparison is New Keynesian models of demand constrained economies (Christiano et al., 2005; Hall, 2005; Smets and Wouters, 2007; Hagedorn and Manovskii, 2008; Galí et al., 2011). The main difference between these papers and mine is, as indicated above, that they insert price or wage rigidities or both to achieve output gaps, while the model of this paper imposes no such restriction. Moreover, the gap in these models is out-of-equilibrium, so to speak, while it is the 'longrun' equilibrium in mine. If given enough time to adjust, economies in New Keynesian models always revert back to full employment. This does not happen in the model of this paper. More recently, Christiano et al. (2016) combine the New Keynesian framework with search frictions to generate equilibrium unemployment and positive output gap (Christiano et al., 2016). However, they assume both price rigidities ala Calvo and labor market frictions, while the purpose of my paper is to demonstrate that even in the absence of the above assumptions one can obtain a demand-constrained equilibrium.

Other models of equilibrium unemployment involve search models, both random (Mortensen and Pissarides, 1994; Burdett and Mortensen, 1998; Herz and Van Rens, 2015; Mangin, 2015) and, more recently, directed search models (Burdett et al., 2001; Galenianos and Kircher, 2009; Menzio and Shi, 2011; Menzio et al., 2016), and asymmetric information models (Shapiro and Stiglitz, 1984). These, however, are supply-side models of imperfect labor markets, where frictions impede labor demand from equalising with labor supply. This paper shows that, even when labor markets are frictionless, unemployment may arise as an equilibrium phenomenon, if aggregate demand is sufficiently weak.

Thus, indirectly, the paper is also related to the theoretical literature on minimumwage policies and unemployment (Stigler, 1946; Bhaskar and To, 1999; Bhaskar et al., 2002). These papers emphasize the role of local monopsonies or imperfect labor-market competition in creating unemployment and how minimum-wage policies may reduce it by encouraging labor force participation. However, these results are based on partial, not general, equilibrium models, where firms' profits do not generate demand for final products. On the contrary, this paper adopts a general equilibrium approach with perfect labor-market competition. 
Another strand of relevant literature is the one on capitalist spirit (Zou, 1994, 1995; Bakshi and Chen, 1996) and the status effects of wealth (Hopkins and Kornienko, 2004; Becker et al., 2005). Capitalist-spirit preferences have been used in macroeoconomic models in the context of growth (Zou, 1994), savings and investment decisions (Zou, 1998; Carroll, 2000; Gong and Zou, 2001; Luo and Young, 2009; Suen, 2014) and, recently, financial crises and business cycles (Karnizova, 2010; Kumhof et al., 2015). These models are dynamic, as opposed to mine, which is static, and they use competitive equilibrium as their solution concept. As a result they do not produce a long-run output gap. This paper, on the other hand, emphasizes the role of fixed-supply goods, like status goods, and the value of a game theoretic approach to model demand-constrained economies.

Last, but not least, is the topic of income and wealth inequality in relation to the weakness of aggregate demand. Several empirical studies have documented the rise in both types of inequality in western economies (Piketty and Saez, 2003; Blundell and Etheridge, 2010; Heathcote et al., 2010; Piketty, 2011; Attanasio et al., 2012; Kopczuk, 2015; Saez and Zucman, 2016). Many economists have also expressed their concern for its harmful consequences to politics (Acemoglu and Robinson, 2015) or to social peace (Piketty, 2014). However, far less attention has been paid by academic economists to its economic consequences (Rajan, 2011; Summers, 2014b), partially because there are very few models which link economic inequality to aggregate demand. One of the main purposes of this paper is to provide a theoretical link between the two.

The rest of the paper is organised as follows. Section 2 presents the model, section 3 presents the main analysis and the main features of the equilibrium, section 4 provides the comparative statics exercises and discusses the wider implications of the model, and, finally section 5 concludes.

\section{The Model}

There are two classes of citizens, workers and entrepreneurs. Each class is homogeneous with respect to its characteristics. Workers provide labor supply, entrepreneurs set prices and wages, hire workers for their firm, and produce the final product. Both classes are consumers of output. The class of workers has $H$ members in total, with $h \in H$ being a generic worker. The class of entrepreneurs has $E$ members in total, with $e \in E$ being a generic member. On aggregate, $E+H=I$, with $i \in I$ being a generic 
citizen.

There are two goods in the economy, one is a producible and consumable commodity, the other one is in fixed supply, it is used as a measure of wealth, and as means of payment. I refer to the former good as the 'commodity', and to the latter as the 'status good'. One can think of the first as the standard good used in economic modelling and the second as 'gold' or 'money' in the economy. Citizens receive utility from both goods. The utility function of citizen $i$ is $u_{i}\left(c_{i}, w_{i}\right)$, where $c_{i}$ is $i$ 's consumption of the commodity and $w_{i}$ is the final holding of wealth, i.e. the final stock holding of the status good. By definition, $w_{i}=w_{i 0}+y_{i}-p c_{i}$, that is the final stock holding of wealth is equal to $i$ 's initial endowment of status good $w_{i 0}$, plus his income $y_{i}$ minus his expenditure $p c_{i}$ where $p$ is the price of the commodity in terms of the status good. $\hat{w}_{i}$ denotes $i$ 's wealth before expenditure: $\hat{w}_{i}=w_{i 0}+y_{i}$. Finally, the usual assumptions on $u_{i}$ hold: $u_{i c}>0, u_{i c c}<0, u_{i w}>0, u_{i w w}<0$, where $u_{i j}$ and $u_{i j j}$ are the first and second partial derivatives of $u_{i}$ with respect to $j$ respectively.

\section{Workers}

Each worker has fixed labor supply equal to $\ell_{0}$ and an initial wealth endowment $w_{\ell 0}$. A worker $h$ may be employed or unemployed. If he is employed, then he receives the wage income $y_{h}=v_{e} \ell_{0}$, where $v_{e}$ is the wage rate that entrepreneur $e$ pays to his workers. If $h$ is unemployed then he has no income. The minimum possible wage rate is exogenously set to $\underline{v} \geq 0$. h's only essential decision is how many units of the commodity to purchase and consume. That is, a worker maximizes $u_{h}\left(c_{h}, w_{h}\right)$ subject to $p c_{h} \leq \hat{w}_{h}$. For convenience, $\hat{w}_{\ell}, \hat{w}_{u}, c_{\ell}^{*}(p)$ and $c_{u}^{*}(p)$ denote the wealth before expenditure and the commodity demands of the employed and unemployed workers respectively. $v_{h}\left(p, \hat{w}_{h}\right)$ denotes $h$ 's indirect utility.

\section{Entrepreneurs}

Entrepreneurs, apart from being consumers, are responsible for the production decisions in the economy. Specifically, each entrepreneur $e$ owns a firm through which he hires workers to produce the commodity. All entrepreneurs have access to the same linear production technology but they do not have labor supply of their own. For every labor unit they employ they get $\alpha$ commodity units. Thus, $e$ 's output is equal to $\alpha \ell_{0} L_{e}$, where $L_{e}$ denotes $e$ 's number of employees. $e$ makes three decisions as producer: (i) He sets 
the price for his product $p_{e}$. (ii) He sets his wage rate $v_{e}$. (iii) He sets his labor demand $\ell_{e}^{d}$ which is expressed in terms of worker numbers. Effectively, $\ell_{e}^{d}$ denotes the number of vacancies $e$ is posting. $e$ 's final output is a joint-outcome of both the labor-market and the commodity-market competition which, in turn, depend on all other entrepreneurs' production decisions. For convenience, the list of vectors $\left\{\mathbf{p}, \mathbf{v}, \ell^{d}\right\}$ denotes the vector of prices, wage rates, and labor demands respectively set by all entrepreneurs. The list of vectors $\left\{\mathbf{p}_{-e}, \mathbf{v}_{-e}, \boldsymbol{\ell}_{-e}^{d}\right\}$ denotes the vector of prices, wage rates, and labor demands respectively set by entrepreneurs excluding $e$. The modelling assumptions of labormarket and commodity-market competition are defined below.

\section{Labor-Market Competition}

I assume perfect labor-market competition, which is modelled as follows. Given the vectors $\mathbf{v}$ and $\ell^{d}$, and the fixed aggregate labor supply $H$, entrepreneurs fill-up their vacancies by absolute priority based on the ranking of their wage rates from the highest to the lowest. That is, the set of entrepreneurs with the highest wage rate fill up their vacancies first, the set of entrepreneurs with the second highest wage rate fill up their vacancies second, and so on, until the pool of workers is exhausted. This implies that, if $L^{d} \equiv \sum_{e} \ell_{e}^{d}<H$, then all entrepreneurs fill their vacancies and a number of workers equal to $H-L^{d}$ remain unemployed. On the other hand, if $L^{d}>H$, then all workers are employed and some entrepreneurs do not fill their vacancies, hence they do not produce. Specifically, in this case, there exists a wage rate $\hat{v}$ and a number of entrepreneurs $E_{\hat{v}} \equiv \#\left\{e \in E \mid v_{e}=\hat{v}\right\}$, such that: (i) $L_{e}=\ell_{e}^{d}$ for all $e$ with $v_{e}>\hat{v}$ (all entrepreneurs with higher wage rates than $\hat{v}$ fill up their vacancies in full). (ii) $L_{e}=0$ for all $e$ with $v_{e}<\hat{v}$ (all entrepreneurs with lower wage rates than $\hat{v}$ do not receive any worker). (iii) $L_{e}=\left[E_{\hat{v}}\right]^{-1}\left(H-\sum_{\left\{e \mid v_{e}>\hat{v}\right\}} \ell_{e}^{d}\right)$ for all $e$ with $v_{e}=\hat{v}$. In the last case I assume that, if $\sum_{\left\{e \mid v_{e} \geq \hat{v}\right\}} \ell_{e}^{d}>H>\sum_{\left\{e \mid v_{e}>\hat{v}\right\}} \ell_{e}^{d}$, then entrepreneurs with $v_{e}=\hat{v}$ share the remainder of the labor-supply pool equally among them.

Implicitly, the labor-market competition sets the cap $\alpha \ell_{0} L_{e}$ to the output of entrepreneurs. Also note that, because workers suffer no costs from moving from one firm to another, and because workers strictly prefer to work for the firm with the highest wage rate, the above formulation of the labor market is equivalent in terms of outcomes to a game where workers observe the wage-rate vector $\mathbf{v}$ and they simultaneously apply for a vacancy. The only additional assumption needed in this case is that, whenever a worker is indifferent between two firms, he applies to both with equal probability. 


\section{Commodity-Market Competition}

Every entrepreneur has two sources of demand for his firm's commodity. The first source is the entrepreneur himself, that is $e$ always consumes the commodity from the production of his firm. ${ }^{1}$ The second source is the product demand by the worker class. I assume that, given the price vector $\mathbf{p}_{e}=\left\{p_{e}, \mathbf{p}_{-e}\right\}$, the fraction of workers that purchases the commodity from $e$ firm is equal to $\mu_{e}\left(p_{e}, \mathbf{p}_{-e}\right)$ and satisfies the following assumptions:

$$
\begin{array}{ll}
\text { (i) } 0 \leq \mu_{e}\left(p_{e}, \mathbf{p}_{-e}\right) \leq 1 \quad \text { (ii) } \sum_{e \in E} \mu_{e}\left(p_{e}, \mathbf{p}_{-e}\right)=1 \\
\text { (iii) if } p_{e}=\hat{p} \forall e \in E & \text { then } \mu_{e}(\hat{p})=E^{-1} \\
\text { (iv) }-\infty<\frac{\partial \mu_{e}}{\partial p_{e}}<0 & \text { (v) } \lim _{p_{e} \rightarrow \infty} \frac{\partial \mu_{e}}{\partial p_{e}}=-\infty
\end{array}
$$

Conditional on $\mu_{e}\left(p_{e}, \mathbf{p}_{-e}\right)$, each of the workers who buy from $e^{\text {'s }}$ firm expresses a consumer demand $c_{h}^{*}\left(p_{e}\right)$, which is derived from the worker's maximization problem and depends on the worker's employment status. Generically, $c_{\ell}^{*}\left(p_{e}\right) \neq c_{u}^{*}\left(p_{e}\right)$. Thus, the total product demand for e's firm is equal to:

$$
D_{e}(\mathbf{p}) \equiv c_{e}+\mu_{e}\left(p_{e}, \mathbf{p}_{-e}\right)\left[L c_{\ell}^{*}\left(p_{e}\right)+(H-L) c_{u}^{*}\left(p_{e}\right)\right]
$$

where $L$ is the total number of employed workers. The aggregate product demand in the economy is equal to $\sum_{e \in E} D_{e}(\mathbf{p})$. Note that the above formulation of each entrepreneurs demand assumes that the same fraction of employed and unemployed workers are customers from one firm, i.e. the proportion of e's customers is independent of their employment status. This assumption is crucial for the existence of symmetric equilibria (see also section 3).

Even though the above specification of commodity-market competition is ad hoc, it is flexible enough to account for both perfect competitive markets and local monopolies. Specifically, when $\frac{\partial \mu_{e}}{\partial p_{e}}=-\infty$ for any $p_{e}$, then the model converges to one of perfect market competition, where the elasticity of demand with respect to price is infinite. On the other hand, when $\frac{\partial \mu_{e}}{\partial p_{e}}=0$ for all $p_{e}$ then the model becomes one of local monopolies, with each entrepreneur's customer base unaffected by the pricing decisions of others.

\footnotetext{
${ }^{1}$ This assumption is without loss of generality. One can easily relax it while obtaining the same main results.
} 
Finally, in the intermediate cases where $-\infty<\frac{\partial \mu_{e}}{\partial p_{e}}<0$, the model is one of imperfect market competition. I focus on the analysis of the intermediate case for the time being, but I discuss the model's results in the two limit cases at the end of section 3.

\section{Firms' Profit Function and Entrepreneurs' Problem}

Given the above specifications of labor and commodity-market competition, $e$ 's firm total output is the minimum of its product demand and its production capacity:

$$
\min \left\{D_{e}(\mathbf{p}), \alpha \ell_{0} L_{e}\right\}
$$

And $e$ 's profit function is given by:

$$
\pi_{e} \equiv\left(p_{e}-v_{e} \alpha^{-1}\right) \min \left\{D_{e}(\mathbf{p})-c_{e}, \alpha \ell_{0} L_{e}\right\}-v_{e} \alpha^{-1} c_{e}
$$

Note that an entrepreneur's profits must be non-negative in equilibrium. Otherwise, he is always better off by closing down his firm and purchasing the commodity with his initial endowment $w_{e 0}$. Thus, an entrepreneur's problem is to maximize his utility $u_{e}\left(c_{e}, w_{e}\right)$ with respect to $\left\{c_{e}, p_{e}, v_{e}, \ell_{e}^{d}\right\}$ subject to $w_{e}=w_{e 0}+\pi_{e}, \pi_{e} \geq 0,(1)$, and the output constraint $D_{e}(\mathbf{p}) \leq \alpha \ell_{0} L_{e}$.

\section{Equilibrium}

An entrepreneur's utility implicitly depends on the other entrepreneurs' decisions through their impact on labor-market competition, commodity-market competition and, thus, on his firm's profits. To make this clear in our notion of equilibrium, I adopt the notation $v_{e}\left(c_{e}, p_{e}, v_{e}, \ell_{e}^{d} \mid\left\{\mathbf{p}_{-e}, \mathbf{v}_{-e}, \ell_{-e}^{d}\right\}\right) \equiv u_{e}\left(c_{e}, w_{e}\left(p_{e}, v_{e}, \ell_{e}^{d} \mid\left\{\mathbf{p}_{-e}, \mathbf{v}_{-e}, \ell_{-e}^{d}\right\}\right)\right)$ in the definitions below.

Definition 1 A Nash equilibrium of the economy is a list of E-length vectors $\left\{\mathbf{p}^{*}, \mathbf{v}^{*}, \ell^{d *}\right\}$ and a H-length vector $\left\{\mathbf{c}^{*}\right\}$ such that: (i) $v_{e}\left(c_{e}^{*}, p_{e}^{*}, v_{e}^{*}, \ell_{e}^{d *} \mid\left\{\mathbf{p}_{-e}^{*}, \mathbf{v}_{-e}^{*}, \ell_{-e}^{d *}\right\}\right) \geq v_{e}\left(c_{e}, p_{e}, v_{e}, \ell_{e}^{d} \mid\right.$ $\left.\left\{\mathbf{p}_{-e}^{*}, \mathbf{v}_{-e}^{*}, \ell_{-e}^{d *}\right\}\right)$ for all $\left\{c_{e}, p_{e}, v_{e}, \ell_{e}^{d}\right\}$ consistent with $\pi_{e} \geq 0$ for all $e \in E$, (ii) $u_{h}\left(c_{h}^{*}, w_{h}\right) \geq$ $u_{h}\left(c_{h}, w_{h}\right)$ under $p c_{h} \leq \hat{w}_{h}$ for all $h \in H$, (iii) $\alpha \ell_{0} \sum_{e \in E} L_{e}=\sum_{i \in I} c_{i}^{*}\left(p_{i}^{*}\right)$.

The above definition is the standard definition of Nash equilibrium with the addition of the condition that total production must be consistent with aggregate demand for the commodity. 
Definition 2 The vector $\left\{p^{*}, v^{*}, \ell^{d *}, c_{e}^{*}, c_{\ell}^{*}\left(p^{*}\right), c_{u}^{*}\left(p^{*}\right)\right\}$ is a pure symmetric Nash equilibrium of the economy if it satisfies the conditions of definition (1).

In words, a pure symmetric Nash equilibrium is a Nash equilibrium of the economy where all entrepreneurs make the same decisions $p_{e}=p^{*}, v_{e}=v^{*}, c_{e}=c_{e}^{*}$ and $\ell_{e}^{d}=\ell^{d *}$. The main analysis of the model focuses on this type of equilibria. However, the following result holds for all equilibria.

Lemma 1 In any Nash equilibrium of the economy $v_{e}=\underline{v}$ for all $e \in E$.

Proof: First, the entrepreneur's profit constraint $\pi_{e} \geq 0$ implies that $p_{e}>v_{e} \alpha^{-1}$. Second, if $\ell_{e}^{d}>\left(\alpha \ell_{0}\right)^{-1} D_{e}(\mathbf{p})$, e suffers additional cost without additional benefit by setting his labor demand above what he needs for production, while if $\ell_{e}^{d}<\left(\alpha \ell_{0}\right)^{-1} D_{e}(\mathbf{p})$, $e$ loses the additional profit from potential customers who demand $e$ 's commodity but can not buy it. Thus, $\ell_{e}^{d}=\left(\alpha \ell_{0}\right)^{-1} D_{e}(\mathbf{p})$ for any $e$. Next, note that there can not exist a Nash equilibrium with $L^{d}>H$. Suppose this is the case. Then, there exists at least one entrepreneur who faces excess demand: $L_{e}=\left[E_{\hat{v}}\right]^{-1}\left(H-\sum_{\left\{e \mid v_{e}>\hat{v}\right\}} \ell_{e}^{d}\right)<$ $\ell_{e}^{d}=\left(\alpha \ell_{0}\right)^{-1} D_{e}(\mathbf{p}) \Rightarrow \alpha \ell_{0} L_{e}<D_{e}(\mathbf{p})$. But in this case $\partial \pi_{e} / \partial p_{e}>0$ so $p_{e}$ can not be optimal. Therefore, an equilibrium is possible only if $L^{d} \leq H$. Finally, $L^{d} \leq H \Rightarrow L_{e}=\ell_{e}^{d} \leq H-\sum_{\{f \in E, f \neq e\}} \ell_{f}^{d}$. In this case, $\partial \pi_{e} / \partial v_{e}<0$, so any $v_{e}>\underline{v}$ is suboptimal. Hence, $v_{e}=\underline{v}$ is the only optimal best-response in equilibrium.

Lemma (1) contains two simple results. The first one is that, in equilibrium, there can not be excess demand for labor because this implies excess product demand, which the entrepreneurs can benefit from simply by raising prices slightly. Second, since equilibrium labor demand is at most equal to labor supply, entrepreneurs do need need to worry about labor market competition. This is because, if one of them reduces his wage rate slightly, even if he were to be the last one to fill his vacancies, he will still be able to get all the workers he demands. Thus labor market competition is mute in the presence of endogenous product demand and the only equilibrium wage rate is the minimum possible. Note that both these arguments are general and do not rely on any additional conditions. However, for the rest of the analysis I focus on pure symmetric equilibria, since they are easy to characterize. The following proposition provides the necessary conditions for a symmetric pure equilibrium.

Proposition 1 Let $\tau_{1}, \tau_{2}$, and $\tau_{3}$ be the Langrange multipliers associated with the conditions $w_{e}=w_{e 0}+\pi_{e}, \pi_{e} \geq 0$, and $D_{e}(\mathbf{p}) \leq \alpha \ell_{0} L_{e}$ respectively. Then the necessary 
conditions for any symmetric pure Nash equilibrium where all entrepreneurs produce are:

$$
\begin{aligned}
& v^{*}=\underline{v} \\
& c_{h}^{*}: \quad u_{h c}=p u_{h w} \quad h \in\{\ell, u\} \\
& c_{e}^{*}: \quad u_{e c}=\underline{v} \alpha^{-1}\left(\tau_{1}+\tau_{2}\right)+\tau_{3} \\
& p^{*}: \quad\left(\tau_{1}+\tau_{2}\right) \frac{\partial}{\partial p_{e}}\left\{\left(p_{e}-\underline{v} \alpha^{-1}\right)\left[D_{e}(\mathbf{p})-c_{e}\right]\right\}=\tau_{3} \frac{\partial D_{e}(\mathbf{p})}{\partial p_{e}} \\
& \tau_{2} \pi_{e}^{*}=0 \quad \forall e \in E \\
& \tau_{3}\left[\alpha \ell_{0} H E^{-1}-D_{e}(\mathbf{p})\right]=0 \\
& L^{*}=\frac{H c_{u}^{*}+E c_{e}^{*}}{\alpha \ell_{0}-\left(c_{\ell}^{*}-c_{u}^{*}\right)}
\end{aligned}
$$

(E1) comes from Lemma 1 directly. (E2) and (E3) come from the first order conditions of workers and entrepreneurs with respect to consumption. (E4) is the entrepreneurs' first order condition with respect to price, while (E5) and (E6) are the Kuhn-Tucker conditions for non-negative profits and the output constraint respectively. Finally, (E7) provides the equilibrium employment and it comes directly from the commodity-clearing condition (iii) of Definition 1.

Proposition 2 A symmetric pure Nash equilibrium always exists.

Proof: In accordance with Lemma 1 , set $v_{e}=\underline{v}$ for all $e \in E$. Suppose that all entrepreneurs set the same price $p$ and the resulting demand functions $c_{\ell}^{*}\left(p, \hat{w}_{\ell}\right)$, $c_{u}^{*}\left(p, \hat{w}_{u}\right)$, and $c_{e}^{*}\left(p, \hat{w}_{e}, \underline{v}\right)$ satisfy the respective conditions of Proposition 1. Let us separate two cases, one where the output constraint does not bind and one where it binds. When the output constraint does not bind, $\tau_{3}=0$ and then (E4) rewrites as $L c_{\ell}^{*}+(H-L) c_{u}^{*}=-E \frac{\partial\left(D_{e}-c_{e}^{*}\right)}{\partial p_{e}}\left(p^{*}-\underline{v} \alpha^{-1}\right)$, which implicitly defines a correspondence between $p$ and $L$. At the same time (E7) implicitly defines a correspondence between $L$ and $p$. It is convenient to define both relations in terms of employment. Thus, define:

$$
p_{s}(L) \equiv\left\{p: L c_{\ell}^{*}+(H-L) c_{u}^{*}=-E \frac{\partial\left(D_{e}-c_{e}^{*}\right)}{\partial p_{e}}\left(p-\underline{v} \alpha^{-1}\right)\right\}
$$




$$
p_{d}(L) \equiv\left\{p: L=\frac{H c_{u}^{*}+E c_{e}^{*}}{\alpha \ell_{0}-\left(c_{\ell}^{*}-c_{u}^{*}\right)}\right\}
$$

The first result is that, in the limit, as $L \rightarrow H, p_{s}(H) \geq p_{d}(H)$. Suppose the contrary, that is suppose $p_{s}(H)<p_{d}(H)$. In this case, the aggregate product demand that entrepreneurs face at $p_{d}(H)$ is, by definition, equal to $\alpha \ell_{0} H$, while the aggregate product demand that they face at the lower price $p_{s}(H)$ exceeds $\alpha \ell_{0} H$, since $\partial c_{h}^{*} / \partial p<0$. But this violates the optimality of $p_{s}(H)$ since firms can always increase their profits by increasing the price when faced with excess demand. Hence, $p_{s}(H) \geq p_{d}(H)$. Next, there exists a weakly positive level of $L$, say $0 \leq \tilde{L} \leq H$, such that $\lim _{L \rightarrow \tilde{L}} p_{d}(L)=+\infty$.

This is because $\lim _{p \rightarrow+\infty} c_{\ell}^{*}=\lim _{p \rightarrow+\infty} c_{u}^{*}=0$ and $0 \leq \lim _{p \rightarrow+\infty} c_{e}^{*} \leq \alpha \underline{v}^{-1}\left(w_{e 0}+E^{-1} \sum_{h} w_{h 0}\right)$. The last inequality holds because entrepreneurs' aggregate expenditure on wages can never exceed aggregate wealth and this limits their maximum consumption. Thus, if $\lim _{p \rightarrow+\infty} c_{e}^{*}=0$, then $\tilde{L}=\lim _{p \rightarrow+\infty} \frac{H c_{u}^{*}+E c_{e}^{*}}{\alpha \ell_{0}-\left(c_{\ell}^{*}-c_{u}^{*}\right)}=0$, or, if $\lim _{p \rightarrow+\infty} c_{e}^{*}>0$, then $0<\tilde{L}=$ $\lim _{p \rightarrow+\infty} \frac{H c_{u}^{*}+E c_{e}^{*}}{\alpha \ell_{0}-\left(c_{\ell}^{*}-c_{u}^{*}\right)} \leq H$. In either case there exists $\tilde{L}$ such that $\lim _{L \rightarrow \tilde{L}} p_{d}(L)=+\infty$. However, $p_{s}(\tilde{L})<+\infty$ since $p_{s}(L)$ is always bounded for any value of $L$ by merit of assumption $(\mathrm{v})$ on $\mu_{e}(\boldsymbol{p})$. Thus, $\lim _{L \rightarrow \tilde{L}} p_{s}(L)-p_{d}(L)<-\infty$ and $p_{s}(H)-p_{d}(H) \geq 0$. Hence, by the fact that $p_{s}(L)$ and $p_{d}(L)$ are both continuous graphs of $p$ with respect to $L$, there exists $L^{*}, \tilde{L}<L^{*} \leq H$, such that $p_{s}\left(L^{*}\right)=p_{d}\left(L^{*}\right)=p^{*}$, and a symmetric pure Nash equilibrium exists.

The second possible case is when $\tau_{3}>0$. In this case the output constraint binds, so (E6) and (E7) converge to $\alpha \ell_{0} H=H c_{\ell}^{*}+E c_{e}^{*}$, which implicitly depends on $p^{*}$ but not $L$. The equilibrium price is then determined either by $u_{e c}\left[1-p^{*}\left(1+\epsilon_{c \mid p}^{-1}\right)+\underline{v} \alpha^{-1}\right]=$ $u_{e w} \underline{v} \alpha^{-1}$, when the profit constraint does not bind, where $\epsilon_{c \mid p}$ is the elasticity of the workers' demand with respect to the price level, or by $p^{*} c_{\ell}^{*}=\underline{v} \ell_{0}$, when the profit constraint binds. In both cases, an equilibrium price $p^{*}$ and employment level $L^{*}=H$ exist, so a pure symmetric Nash equilibrium exists.

Although the equilibrium existence is a reassuring result, the interesting feature of the model is the fact that the equilibrium does not always entail full employment, or, to put it differently, it may entail a positive output gap. This is in stark contrast to competitive equilibrium models, which are usually used for macroeconomic modelling. 
Thus a pure symmetric equilibrium without full employment means that the production constraint is non-binding and $\tau_{3}=0$. In this case, the equilibrium is characterised by the pricing equation $p_{s}(L)$ and the employment equation (E7). The former can be viewed as an aggregate supply equation that gives the firms optimal pricing choice conditional on employment conditions and the commodity demand that they generate. The latter is an effective aggregate demand equation, giving the employment level consistent with commodity demand conditional for each price level. Figure 1 below demonstrates different possible shapes for the correspondences $p_{s}(L)$ and $p_{d}(L)$ and how they can generate economies with multiple or unique equilibria and with or without unemployment.

An equilibrium with positive output gap/unemployment may result in the case where both workers and entrepreneurs have relatively weak demand for the commodity in comparison to the status good, or, in other words, the marginal utility for the commodity declines at a substantially faster rate than the marginal utility of the status good. In this case, the profit constraint may or may not be binding, but the weak aggregate demand for the commodity translates into weak labor demand and unemployment. Thus, effective commodity competition does not automatically imply full employment. The value of the status good relative to that of the commodity matters too.

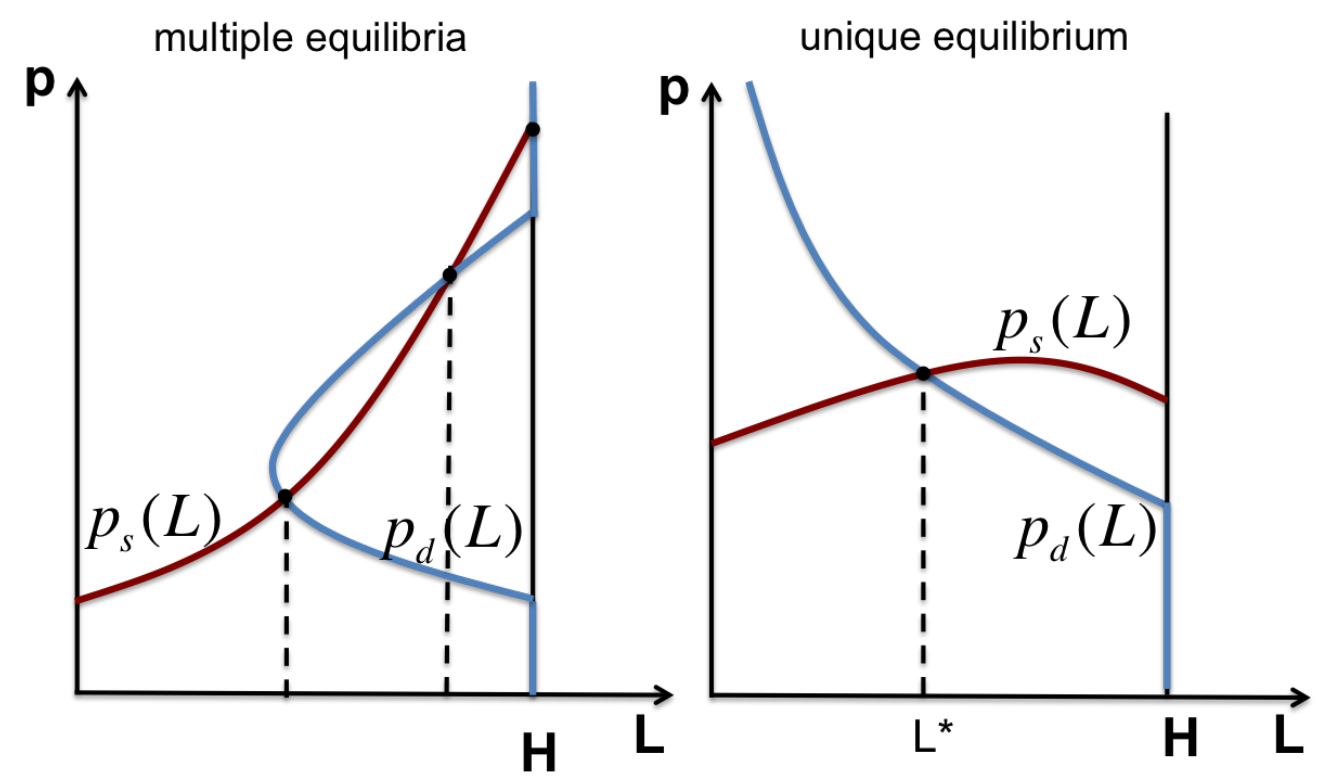

Figure 1: Positive Equilibrium Output Gap and Unemployment

Another possible case where a positive output gap may arise in equilibrium is when 
workers have strong demand for the commodity, but entrepreneurs have strong preference for the status good and commodity competition is relatively weak so that the profit constraint is non-binding. In this case, even though high level of commodity competition across entrepreneurs may be enough to lead to full employment, the lack of it, along with weak commodity demand by entrepreneurs leads to low aggregate labor demand. In this case, an increase in wealth or income inequality may widen the output gap, as the loss of demand by workers is only partially compensated by the increased demand by entrepreneurs. I try to make this more clear in the next section, where I conduct comparative statics.

To present the above arguments in a more concrete manner consider the following example with explicit functional forms. First, suppose that the utility function of an agent $i$ is given by $u_{i}\left(c_{i}, w_{i}\right)=\epsilon_{i} \ln \left(c_{i}\right)+\ln \left(w_{i}\right)$, for $i \in\{h, e\}$, where $\ln ($.$) is the natural$ logarithm function. Second, suppose that $\mu_{e}\left(p_{e}, \mathbf{p}_{-e}\right)$ is given by the expression below:

$$
\mu_{e}\left(p_{e}, \mathbf{p}_{-e}\right)= \begin{cases}E^{-1}+\mu \frac{p^{m i n}-p_{e}}{p^{m a x}-p^{m i n}+\delta} & \text { if } p_{e}>p^{\text {min }} \\ {\left[N\left(p^{m i n}\right)\right]^{-1}\left(1-\sum_{p_{f} \neq p^{\text {min }}} \mu_{f}\left(p_{f}, \mathbf{p}_{-f}\right)\right)} & \text { if } p_{e}=p^{\text {min }}\end{cases}
$$

where $p^{\max }=\max \left\{p_{e}: p_{e} \in \mathbf{p}\right\}, p^{\min }=\min \left\{p_{e}: p_{e} \in \mathbf{p}\right\}, N\left(p^{\min }\right)$ is the number of entrepreneurs with the minimum price in $\mathbf{p}$, and $\mu, \delta$ are positive constants.

Under these functional forms, the demand function is $c_{h}^{*}=\frac{\epsilon_{h}}{1+\epsilon_{h}} \frac{\hat{w}_{h}}{p}$ for workers and $c_{e}^{*}=\frac{\epsilon_{e}}{1+\epsilon_{e}} \frac{\hat{w}_{e}}{\underline{v} \alpha^{-1}}$ for entrepreneurs. Next, postulating a pure symmetric equilibrium with positive output gap and positive profits for entrepreneurs, which implies zero values for the Langrangian multipliers $\tau_{2}$ and $\tau_{3}$, and computing the optimal best-response with respect to the price level gives the unique optimal price $p^{*}=$ $2^{-1}\left(x_{2}+\sqrt{x_{2}^{2}+4 E^{-1} x_{1}^{-1} x_{2}}\right)$, where $x_{1} \equiv \mu \delta^{-1}$ and $x_{2} \equiv \underline{v} \alpha^{-1}$, which is independent of the employment level $L$ of the economy. Combining the above with (E7) one obtains the unique employment level given by:

$$
L^{*}=\frac{H \epsilon_{h} w_{h 0}\left[\left(1+\epsilon_{e}\right) / p^{*}+\alpha \epsilon_{e} / \underline{v}\right]+\alpha E \epsilon_{e}\left(1+\epsilon_{h}\right) w_{e 0} / \underline{v}}{\alpha \ell_{0}\left[\left(1+2 \epsilon_{e}\right)\left(1+\epsilon_{h}\right)-\epsilon_{e} \epsilon_{h}\right]-\epsilon_{h}\left(1+\epsilon_{e}\right) \underline{v} \ell_{0} / p^{*}}
$$

The conjecture about the equilibrium featuring both positive output gap and profits is correct if $L^{*}<H$ and $\pi_{e}\left(p^{*}\right)>0$. The proposition below gives the necessary conditions 
for this conjecture to be correct and figure 2 demonstrates the functions $p_{d}(L)$ and $p_{s}(L)$ and the equilibrium in this case.

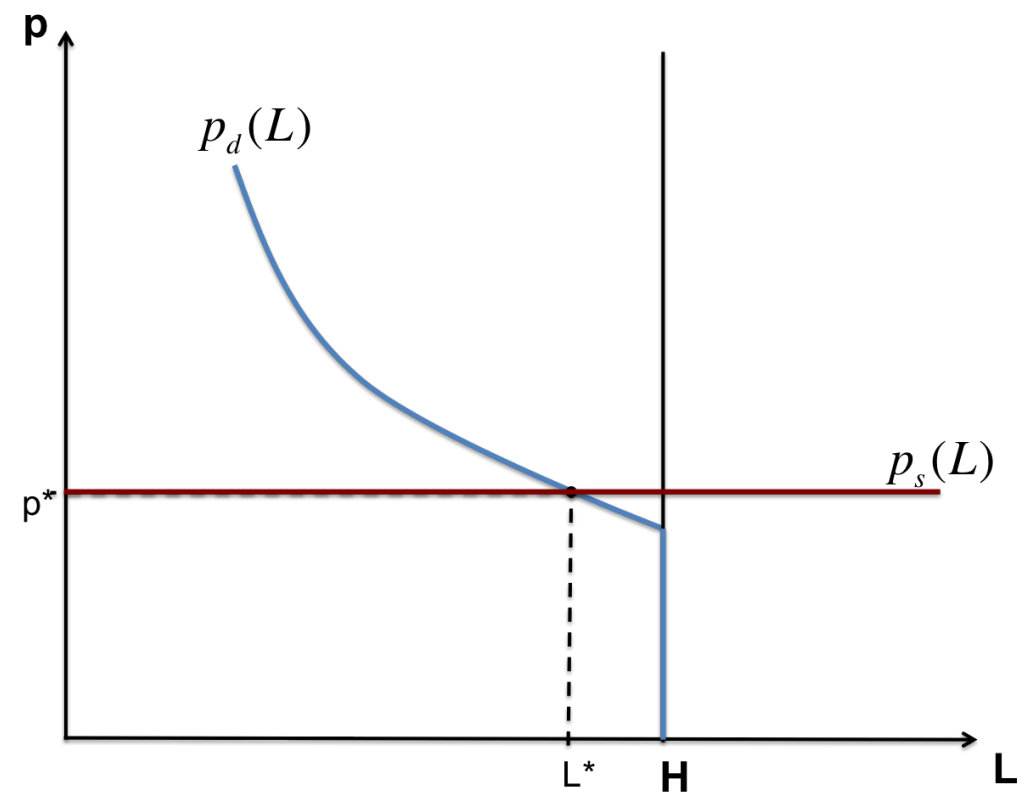

Figure 2: Equilibrium With Explicit Functional Forms

Proposition 3 Consider the economy with the explicit functional forms for $u_{i}$ and $\mu_{e}$ given by $u_{i}\left(c_{i}, w_{i}\right)=\epsilon_{i} \ell n\left(c_{i}\right)+\ell n\left(w_{i}\right)$ and (2) respectively. Then a pure symmetric Nash equilibrium exists with $p^{*}=2^{-1}\left(x_{2}+\sqrt{x_{2}^{2}+4 E^{-1} x_{1}^{-1} x_{2}}\right), L^{*}$ given by (3), and positive output gap, only if the following inequalities hold:

$$
\begin{gathered}
\left(1-\frac{\underline{v}}{\alpha p^{*}}\right)\left(H \epsilon_{h} w_{e 0}+L^{*} \epsilon_{h} \underline{v} \ell_{0}\right)>\epsilon_{e}\left(1+\epsilon_{e}\right)^{-1} w_{e 0} \\
\ell_{0}\left(1+2 \epsilon_{e}\right)+\epsilon_{h}\left(1+\epsilon_{e}\right) \frac{\alpha p^{*} \ell_{0}-\underline{v}_{0}-w_{h 0}}{\alpha p^{*}}>\underline{v}^{-1} \epsilon_{e}\left[\epsilon_{h} w_{h 0}+\left(1+\epsilon_{h}\right) E H^{-1} w_{e 0}\right]
\end{gathered}
$$

Condition (4) is necessary for entrepreneurs to gain positive profits from production, while condition (5) is necessary for obtaining a positive output gap in equilibrium. Note that these conditions are not mutually incompatible. For example, as $\epsilon_{e}$ and $w_{h 0}$ both approach zero, then both conditions hold by the fact that $\alpha p^{*}>\underline{v}$. In fact, in this limit case (3) shows that $L^{*}$ approaches zero. This is intuitive since when $\epsilon_{e}=0$ entrepreneurs get no utility from the commodity, so their demand is zero, and 
when $w_{h 0}=0$ workers have no endowment of the status good which entrepreneurs want to acquire in exchange for the commodity. In general, (3) shows that equilibrium employment is increasing in the initial endowments of status goods for both types of citizens and in the $\epsilon_{i}$ parameter, which indicates the relative value of the commodity vis-á-vis the status good. In the next section we discuss in more detail the effects of redistributive policies for equilibrium employment, as well as the ambiguous role of the productivity parameter and the minimum wage.

Before we conclude this section, however, note that, as the minimum wage approaches zero the economy converges to full employment. This can be easily demonstrated by looking at the first order condition with respect to commodity demand of the entrepreneurs, which is: $u_{e c}-\underline{v} \alpha^{-1}\left(\tau_{1}+\tau_{2}\right)-\tau_{3}$. As $\underline{v}$ approaches zero the condition converges to $u_{e c}=\tau_{3}$. Since the marginal utility of the commodity is always positive, then $\tau_{3}>0$, and, therefore, the production constraint is binding. Intuitively, as the cost of production becomes infinitesimally small, the opportunity cost of entrepreneurs from consuming the commodity vanishes and their demand for it increases. In the limit the economy must approach full employment. The following proposition summarises the above.

Proposition 4 A pure symmetric Nash equilibrium may involve a strictly positive output gap and unemployment: $L^{*}<H$. However, $\lim _{\underline{v} \rightarrow 0} L^{*}(\underline{v})=H$.

Finally, it is worth examining what happens in the two limit cases with respect to commodity competition. The first case is when commodity competition is nonexistent, which corresponds to the assumption that $\partial \mu_{e}\left(p_{e}, \mathbf{p}_{-e}\right) / \partial p_{e}=0$ for all $p_{e}$ and $\mathbf{p}_{-e}$. Then the model becomes one of local monopolies where each entrepreneur has a fraction $1 / E$ of the workers' as customers (but not necessarily his own workers). In this case $\partial\left(D_{e}-c_{e}^{*}\right) / \partial p_{e}=E^{-1}\left(L^{*} c_{\ell}^{*}\left(p^{*}\right)+\left(H-L^{*}\right) c_{u}^{*}\left(p^{*}\right)\right)$ which implies that the $p_{s}(L)$ curve becomes steeper, i.e. the optimal price for the firm is higher than the case of imperfect commodity competition, since the entrepreneur dos not lose customers to other firms. Thus, if there exits a pure symmetric equilibrium with positive output gap in the case of imperfect commodity competition, the output gap is even larger in the limit case of local monopolies, as expected. In other words, the set of parameter values where a symmetric equilibrium with positive output gap exists weakly increases with the decrease in the intensity of competition.

The other limit case is the one of perfect commodity competition, namely the case where $\partial \mu_{e}\left(p_{e}, \mathbf{p}_{-e}\right) / \partial p_{e}=-\infty$ for all $p_{e}$ and $\mathbf{p}_{-e}$. In this case the entrepreneurs' 
participation constraint is always binding: $\pi_{e}=0$. However, the labor supply constraint may or may not be binding, depending on the strength of commodity demand. If the marginal utility for the commodity is sufficiently low then equilibrium unemployment may emerge even in the presence of perfect competition. For example, consider the special case of a quasi-linear utility function of the form $u_{h}\left(c_{h}, w_{h}\right)=\epsilon_{h} \ln \left(c_{h}\right)+\left(w_{h}\right)^{\beta}$, with $\epsilon_{h}>0$ and $0<\beta<1$. Then it is easy to check that as $\epsilon_{h} \rightarrow 0$ then $c_{h}^{*}(p) \rightarrow 0$ and the demand for the producible commodity becomes zero. If both classes have similar preferences then the aggregate demand for the commodity is zero and, hence, it is not produced in equilibrium. This implies that one can always find an $\epsilon_{h}$ small enough but strictly positive, such that the economy features a positive equilibrium gap. On the other hand, if both the profit and the labor supply constraint are binding, then the model gives the canonical result of a perfectly competitive economy with full employment and zero profits.

\section{Comparative Statics and Wider Implications}

The main purpose of this paper is to provide a very simple model where demand-side considerations become crucial in determining the economy's equilibrium behavior. To achieve this purpose, I provide a set of comparative-statics results which go against conventional economic intuition, but make a lot of sense in a model where equilibrium demand is weak and a positive output gap emerges.

\section{Non-Neutral Effects of Income and Wealth Inequality}

Income and wealth inequality have drawn a lot of attention in both public debates and in academic research. Some economists have spoken openly against the dangers of a widening income and wealth gap. But the main dangers cited are either political (Acemoglu and Robinson, 2015) or based on considerations of fairness and social unrest (Piketty, 2014). So far, academic economists have refrained from linking rising income and wealth inequality to the poor economic performance after the Great Recession, with few exceptions (Rajan, 2011; Summers, 2014a). This subsection provides an economic rationale on why increasing levels of income or wealth inequality may be undesirable.

To be more specific, I examine how equilibrium employment responds to small changes in either the minimum wage, which links income inequality to the output gap, or a small redistribution of the entrepreneurs' status-good endowment to workers. 
General comparative statics results are discussed first, but to make the arguments more concrete, results with the explicit functional forms from the previous section are also presented.

For comparative statics with respect to income inequality, consider a small exogenous positive change to the minimum wage $d \underline{v}>0$. By the envelope theorem, this change leads to a net negative effect on the entrepreneurs' profit $\left(d \pi_{e} / d \underline{v}<0\right)$, but it increases employed worker's income by $\ell_{0} d \underline{v}>0$. Thus, it reduces income inequality between entrepreneurs and employed workers. If the economy is output constrained then, clearly, employment can not increase any further and, therefore, the change in the minimum wage has no positive effect on employment. On the contrary, in some cases, it may even be negative. However, if the economy is demand constrained, then, by a direct application of the implicit function theorem, the change in equilibrium employment is given by:

$$
\frac{d L^{*}}{d \underline{v}}=\frac{\Delta_{p} \Sigma_{\underline{v}}-\Delta_{\underline{v}} \Sigma_{p}}{\Delta_{L} \Sigma_{p}-\Delta_{p} \Sigma_{L}}
$$

where

$$
\begin{aligned}
& \Delta \equiv L^{*}-\frac{H c_{u}^{*}+E c_{e}^{*}}{\alpha \ell_{0}-\left(c_{\ell}^{*}-c_{u}^{*}\right)} \\
& \Sigma \equiv L^{*} c_{\ell}^{*}+\left(H-L^{*}\right) c_{u}^{*}+E \frac{\partial\left(D_{e}-c_{e}^{*}\right)}{\partial p_{e}}\left(p^{*}-\underline{v} \alpha^{-1}\right)
\end{aligned}
$$

and $\Delta_{x}\left(\Sigma_{x}\right)$ denotes the partial derivative of $\Delta(\Sigma)$ with respect to $x$.

Even if one focuses attention to cases where the direct effects dominate the indirect effects and the denominator of $d L^{*} / d \underline{v}$ can be signed (in this case $\Delta_{p}>0, \Delta_{L}>0, \Sigma_{p}<$ $0, \Sigma_{L}>0$, so $\left.\Delta_{L} \Sigma_{p}-\Delta_{p} \Sigma_{L}<0\right)$, the signs of $\Delta_{\underline{v}}$ and $\Sigma_{\underline{v}}$ are both ambiguous and the sign of the numerator can be either positive or negative. Thus, the effects of the increase of the minimum wage are ambiguous and it depends on the relative strength between the demand-side and the supply-side channel. If commodity competition is sufficiently strong, so that the increase in wage costs is not fully passed on to consumers $\left(\Sigma_{\underline{v}}\right.$ is relatively small in absolute value), and if the workers' marginal utility of the commodity is sufficiently higher than the one of entrepreneurs, so that the redistribution of income leads to increased aggregate demand $\left(_{\underline{v}}\right.$ is negative and relatively high in absolute value), then the increase of the minimum wage leads to increased employment. The 
opposite holds if commodity competition is weak $\left(\Sigma_{\underline{v}}\right.$ is positive and relatively high) and the effect of redistribution on aggregate demand is weak or negative $\left(\Delta_{\underline{v}}\right.$ is negative or positive and relatively low in absolute value).

To see this more clearly consider the model under the explicit functional forms of section 3. Recall that in this case the equilibrium employment and price level are given by the expressions:

$$
\begin{gathered}
L^{*}=\frac{\alpha \underline{v}^{-1} \epsilon_{e}\left[\epsilon_{h} H w_{h 0}+\left(1+\epsilon_{h}\right) E w_{e 0}\right] p^{*}+\epsilon_{h}\left(1+\epsilon_{e}\right) H w_{h 0}}{\alpha \ell_{0}\left[\epsilon_{e}+\left(1+\epsilon_{e}\right)\left(1+\epsilon_{h}\right)\right] p^{*}-\epsilon_{h}\left(1+\epsilon_{e}\right) \underline{v} \ell_{0}} \\
p^{*}=2^{-1}\left(x_{2}+\sqrt{x_{2}^{2}+4 E^{-1} x_{1}^{-1} x_{2}}\right) \quad \text { where } \quad x_{1} \equiv \mu \delta^{-1}, x_{2} \equiv \underline{v} \alpha^{-1}
\end{gathered}
$$

From the above it is obvious that the direct effect of $\underline{v}$ on $L^{*}$ is ambiguous as an increase in the former decreases both the numerator and the denominator of the fraction. However, as $\epsilon_{e} \rightarrow 0$, the direct effect becomes strictly positive, while as $\epsilon_{h} \rightarrow 0$ the direct effect becomes strictly negative. Thus the direct of the direct effect depends on the relative magnitude of the propensities to consume of the two citizen types, as explained earlier. The higher the marginal utility of workers (entrepreneurs) from the commodity, the more they tend to consume and hence the higher the equilibrium employment as the minimum wage increases (decreases).

On top of this there is the indirect effect through $p^{*}$, which is always negative in this example, since $d p^{*} / d \underline{v}>0$ and $d L^{*} / d p^{*}<0$. Thus, the overall effect is ambiguous. Note, however, that as customer competition intensifies (higher values of $\mu$ ), the size of the indirect effect is reduced $\left(d^{2} p^{*} /(d \underline{v} d \mu)<0\right)$ so that direct effects are more important. This means that an increase in the minimum wage is more likely to generate an increase in employment in economies with strong customer competition (high values of $\mu$ ) and with strong commodity demand by workers (high values of $\epsilon_{h}$. Analytically, this conclusion is best demonstrated in the limit case $\epsilon_{e} \rightarrow 0$, where $L^{*}=\epsilon_{h} H w_{h 0} \ell_{0}^{-1}\left(\alpha p^{*}-\epsilon_{h} \underline{v}\right)^{-1}$. In this case $d L^{*} / d \underline{v} \geq 0$ only if $2 \epsilon_{h} \geq 1+\left(\underline{v}^{2} \alpha^{-2}+4 \underline{v} \delta(\alpha \mu E)^{-1}\right)^{-1 / 2}\left(\underline{v} \alpha^{-1}+2 \delta(\mu E)^{-1}\right)$.

Overall, income distribution is non-neutral when the economy has a positive output gap and increases of the minimum wage can lead to increased employment and output. Therefore, the model has an interesting implication on minimum-wage policies. Contrary to what conventional economic theorists predict, minimum wage policies can have positive economic effects even in the long run.

Next, consider a balanced redistribution of wealth from entrepreneurs to workers. In particular, suppose that before economic activity takes place every entrepreneurs loses 
$d w_{0 e}$ units of wealth which are equally distributed across workers. So, each workers gains $E H^{-1} d w_{0 e}$ units of the status good. By the implicit function theorem one obtains:

$$
\frac{d L^{*}}{d w_{0 e}}=\frac{\Delta_{p} \Sigma_{w}-\Delta_{w} \Sigma_{p}}{\Delta_{L} \Sigma_{p}-\Delta_{p} \Sigma_{L}}
$$

Similarly to above, the effects of the wealth redistribution are non-neutral when the economy is demand constrained and, conditional on direct effects dominating indirect ones, they depend on the sign of $\Delta_{w}$ and $\Sigma_{w}$, which are ambiguous. When commodity competition is strong $\left(\Sigma_{w}\right.$ small in absolute value) and the marginal propensity to consume of workers is higher than entrepreneurs' $\left(\Delta_{w}\right.$ is negative and big in absolute value), then wealth redistribution increases employment and output. The other side of this effect is that an increase in wealth inequality, through a redistribution of wealth from workers to entrepreneurs, has the opposite effect, i.e. it decreases employment and output. However, in the case of weak commodity competition $\left(\Sigma_{w}\right.$ positive and large in absolute value) and small differences in marginal propensities of consumption between the two groups ( $\Delta_{w}$ small in absolute value) employment decreases and small changes to wealth inequality have positive effects on economic activity.

Once again, the example from before is elucidating. Since $p^{*}$ does not depend on individual wealth in this case, there are no indirect effects and, hence, only the change of the numerator matters. In this case the impact of wealth redistribution on equilibrium employment is proportional to $\epsilon_{h}\left[1+\epsilon_{e}+\epsilon_{e} \alpha p^{*} \underline{v}^{-1}\right]-\epsilon_{e}\left(1+\epsilon_{h}\right) \alpha p^{*} \underline{v}^{-1}$ and the effect of the policy is non-negative only if $\epsilon_{h} / \epsilon_{e} \geq \alpha p^{*} \underline{v}^{-1}$, which is interpreted as the ratio of the marginal utility between workers and entrepreneurs being higher than the entrepreneurs' gross profit margin per hour worked. Clearly, then, the higher the marginal utility of workers the more likely is the redistribution of wealth increases the efficiency of the economy. Again, higher intensity of commodity competition (higher values of $\mu$ ) lowers $p^{*}$ and, thus, lowers the required threshold for the redistribution to have positive effects. This is consistent with the interpretation of the role of competition on $\Sigma_{w}$.

\section{Productivity Growth}

Conventional economic intuition suggests that increases in productivity translate to higher employment and output, and academics generally agree with this statement. Yet, this crucially resides on the assumption that the economy is output constrained. The 
model can be used to demonstrate that the same reasoning does not necessarily apply when the economy is demand constrained. In particular, considering the comparative statics implications of a small increase in the productivity parameter $\alpha$, denoted by $d \alpha$. Similarly to the previous subsection, the change in equilibrium employment is given by:

$$
\frac{d L^{*}}{d \alpha}=\frac{\Delta_{p} \Sigma_{\alpha}-\Delta_{\alpha} \Sigma_{p}}{\Delta_{L} \Sigma_{p}-\Delta_{p} \Sigma_{L}}
$$

Once again we focus our attention to the case where direct effects dominate indirect ones, and this implies that $\Delta_{p}>0, \Delta_{L}>0, \Sigma_{p}<0, \Sigma_{L}>0$ and $\Delta_{L} \Sigma_{p}-\Delta_{p} \Sigma_{L}<0$. Because $\Delta_{\alpha}$ and $\Sigma_{\alpha}$ have ambiguous signs, the effect of productivity on equilibrium employment is also ambiguous. This is because, on the one hand, an increase in productivity raises entrepreneurial profits and consumption, which feeds back to an increase in aggregate demand and employment. On the other hand, a productivity increase reduces labor demand, which reduces employment and workers' commodity demand, and feeds back to the initial reduction of employment. Which channel dominates depends on the relative sizes of $\Delta_{\alpha}$ and $\Sigma_{\alpha}$. As longs as $\Delta_{\alpha}$ is negative or small in absolute value and $\Sigma_{\alpha}$ is negative, employment is positively affected by productivity changes. But if $\Sigma_{\alpha}$ is positive (i.e. prices are positively affected by productivity growth), and $\Delta_{\alpha}$ is positive (i.e. aggregate demand falls with productivity increases), then employment and output suffer a negative effect.

In the analytical example presented earlier (see expressions for $L^{*}$ and $p^{*}$ on page 19) the parameter $\alpha$ affects directly $L^{*}$ by increasing both the numerator and the denominator, and, indirectly through reducing $p^{*}\left(d p^{*} / d \alpha<0\right)$. Since an increase in $p^{*}$ decreases $L^{*}$, the indirect effect is always positive. The overall effect is ambiguous. But an interesting case emerges in the limit case when $\epsilon_{e} \rightarrow 0$. Then $L^{*} \rightarrow \frac{H \epsilon_{h} w_{h 0}}{\ell_{0}\left(\alpha p^{*}-\epsilon_{h} \underline{v}\right)}$ and the impact of $\alpha$ on $L^{*}$ depends on the relative magnitude of the elasticity of the price level to productivity: $d L^{*} / d \alpha \leq 0 \Rightarrow-\frac{d p^{*}}{d \alpha} \frac{\alpha}{p^{*}} \leq 1$ or $E_{p \mid \alpha} \leq 1$. Therefore, if the price level is inelastic to productivity increases then increases in the latter reduce equilibrium employment, as the relative purchasing power of workers falls and so do the aggregate expenditure and production. On the other hand, if prices are elastic to productivity increases, then the opposite holds. Increases in productivity increase the relative purchasing power of workers and production and employment increase. This is an interesting finding because it is often invoked by non-academic economists, especially when discussing the impact of technological innovations on the future of labor (Rifkin, 
1996), but academics often dismiss it as theoretically unfounded. ${ }^{2}$ In this example one can see that the distinction between a demand or a supply constrained economy is crucial for the validity of the statement.

\section{Conclusion}

This paper presents a simple model of a demand-constrained economy without any price rigidities, where a positive output gap and unemployment emerge as equilibria phenomena, and where the distribution of income and wealth matter. The main elements that give rise to these results is the presence of a good in fixed supply, which I justify in terms of capitalist-spirit preferences, and the adoption of a game-theoretic approach in solving for the equilibrium. In particular, the focus of the analysis is on pure symmetric Nash equilibria, where agents of the same type take the same actions.

The main intention of the model is to provide a theoretical justification for the attention that demand-side models have received after the Great Recession, and to address the criticism launched against them, that they require ad-hoc assumptions on price rigidities. Furthermore, now that public opinion in many western countries has turned its attention to income inequities, and minimum-wage regulations have been proposed both in US and UK, it is important to provide both theoretical and empirical justifications for their implementation. This paper is a small step in this direction.

\footnotetext{
${ }^{2}$ For more extensive discussions on this topic see that papers by Autor (2015), Mokyr et al. (2015), and Pratt (2015). Sachs et al. (2015) provide a good literature review of the area and a different theoretical argument on why technological improvements may reduce social welfare.
} 


\section{References}

Acemoglu, D. And J. A. Robinson (2015): "The Rise and Decline of General Laws of Capitalism," The Journal of Economic Perspectives, 29, 3-28.

Aghion, P., E. Caroli, and C. Garcia-Penalosa (1999): "Inequality and Economic Growth: The Perspective of the New Growth Theories," Journal of Economic literature, 37, 1615-1660.

Attanasio, O., E. Hurst, and L. Pistaferri (2012): "The Evolution of Income, Consumption, and Leisure Inequality in The US, 1980-2010," NBER Working Paper Series No. 17982.

Autor, D. H. (2015): "Why Are There Still So Many Jobs? The History and Future of Workplace Automation," The Journal of Economic Perspectives, 29, 3-30.

Bakshi, G. S. And Z. Chen (1996): "The Spirit of Capitalism and Stock-Market Prices," The American Economic Review, 86, 133-157.

Becker, G. S., K. M. Murphy, And I. Werning (2005): "The Equilibrium Distribution of Income and The Market for Status," Journal of Political Economy, 113, $282-310$.

Bhaskar, V., A. Manning, And T. To (2002): "Oligopsony and Monopsonistic Competition in Labor Markets," The Journal of Economic Perspectives, 16, 155-174.

Bhaskar, V. And T. To (1999): "Minimum Wages for Ronald McDonald Monopsonies: A theory of Monopsonistic Competition," The Economic Journal, 109, 190203.

Blundell, R. And B. Etheridge (2010): "Consumption, Income and Earnings Inequality in Britain," Review of Economic Dynamics, 13, 76-102.

Burdett, K. And D. T. Mortensen (1998): "Wage Differentials, Employer Size, and Unemployment," International Economic Review, 257-273.

Burdett, K., S. Shi, And R. Wright (2001): "Pricing and Matching with Frictions," Journal of Political Economy, 109, 1060-1085.

Carroll, C. D. (2000): "Why Do the Rich Save So Much?" Working Paper.

Christiano, L. J., M. Eichenbaum, and C. L. Evans (2005): "Nominal Rigidities and the Dynamic Effects of a Shock to Monetary Policy," Journal of political Economy, 113, 1-45.

Christiano, L. J., M. S. Eichenbaum, and M. Trabandt (2016): "Unemployment and Business Cycles," Econometrica, 84, 1523-1569. 
Galenianos, M. And P. Kircher (2009): "Directed Search with Multiple Job Applications," Journal of Economic Theory, 144, 445-471.

Galí, J., F. Smets, And R. Wouters (2011): "Unemployment in an Estimated New Keynesian Model," NBER Macroeconomics Annual, 26, 329-360.

Gong, L. And H.-F. Zou (2001): "Money, Social Status, and Capital Accumulation in a Cash-In-Advance Model," Journal of Money, Credit and Banking, 33, 284-293.

Hagedorn, M. And I. Manovskit (2008): "The Cyclical Behavior of Equilibrium Unemployment and Vacancies Revisited," The American Economic Review, 98, 16921706.

Hall, R. E. (2005): "Employment Fluctuations with Equilibrium Wage Stickiness," The American Economic Review, 95, 50-65.

Heathcote, J., F. Perri, And G. L. Violante (2010): "Unequal We Stand: An Empirical Analysis of Economic Inequality in the United States, 1967-2006," Review of Economic dynamics, 13, 15-51.

Herz, B. And T. VAn Rens (2015): "Accounting for Mismatch Unemployment," IZA Discussion Paper.

Hopkins, E. And T. Kornienko (2004): "Running to Keep in the Same Place: Consumer Choice as a Game of Status," The American Economic Review, 94, 10851107.

Karnizova, L. (2010): "The Spirit of Capitalism and Expectation-Driven Business Cycles," Journal of Monetary Economics, 57, 739-752.

Klenow, P. J. And B. A. Malin (2010): "Microeconomic Evidence on Price-Setting," Handbook of Monetary Economics, 3, 231-284.

KopczuK, W. (2015): "What Do We Know About the Evolution of Top Wealth Shares in the United States?" The Journal of Economic Perspectives, 29, 47-66.

Kumhof, M., R. Rancière, And P. Winant (2015): "Inequality, Leverage, and Crises," The American Economic Review, 105, 1217-1245.

Luo, Y. And E. R. Young (2009): "The Wealth Distribution and the Demand for Status," Macroeconomic Dynamics, 13, 1-30.

Mangin, S. (2015): "Unemployment and the Labor Share," Monash Business School, Dept. of Economics Discussion Paper.

Menzio, G. And S. Shi (2011): "Efficient Search on the Job and the Business Cycle," Journal of Political Economy, 119, 468-510. 
Menzio, G., I. A. Telyukova, And L. Visschers (2016): "Directed Search over the Life Cycle," Review of Economic Dynamics, 19, 38-62.

Mokyr, J., C. Vickers, And N. L. Ziebarth (2015): "The History of Technological Anxiety and the Future of Economic Growth: Is This Time Different?" The Journal of Economic Perspectives, 29, 31-50.

Mortensen, D. T. and C. A. Pissarides (1994): "Job Creation and Job Destruction in the Theory of Unemployment," The Review of Economic Studies, 61, 397-415.

Nakamura, E. And J. Steinsson (2013): "Price Rigidity: Microeconomic Evidence and Macroeconomic Implications," Annu. Rev. Econ, 5, 133-63.

PiketTy, T. (2011): "On the Long-Run Evolution of Inheritance: France 1820-2050," The Quarterly Journal of Economics, 126, 1071-1131.

_ (2014): "Capital in the 21st Century," Cambridge: Harvard University.

Piketty, T. And E. Saez (2003): "Income Inequality in the United States, 19131998," The Quarterly journal of economics, 118, 1-41.

Pratt, G. A. (2015): "Is a Cambrian Explosion Coming For Robotics?" The Journal of Economic Perspectives, 29, 51-60.

RaJan, R. G. (2011): Fault Lines: How Hidden Fractures Still Threaten the World Economy, Princeton University Press.

Rifkin, J. (1996): The End Of Work, Pacifica Radio Archives.

Sachs, J. D., S. G. Benzell, And G. LaGarda (2015): "Robots: Curse or Blessing? A Basic Framework," NBER Working Paper No. w21091.

Saez, E. And G. Zucman (2016): "Wealth Inequality in the United States since 1913: Evidence from Capitalized Income Tax Data," The Quarterly Journal of Economics, $131,519-578$.

Shapiro, C. And J. E. Stiglitz (1984): "Equilibrium Unemployment as a Worker Discipline Device," The American Economic Review, 74, 433-444.

Smets, F. And R. Wouters (2007): "Shocks and Frictions in US Business Cycles: A Bayesian DSGE Approach," The American Economic Review, 97, 586-606.

Stigler, G. J. (1946): "The Economics of Minimum Wage Legislation," The American Economic Review, 36, 358-365.

Suen, R. M. (2014): "Time Preference and the Distributions of Wealth and Income," Economic Inquiry, 52, 364-381. 
Summers, L. H. (2014a): "Reflections on the 'New Secular Stagnation Hypothesis'," Secular Stagnation: Facts, Causes and Cures, 27-40.

(2014b): "US Economic Prospects: Secular Stagnation, Hysteresis, and the Zero Lower Bound," Business Economics, 49, 65-73.

The Economist, F. E. (2014): "Inequality v Growth: Up to a Point, Redistributing Income to Fight Inequality Can Lift Growth," Www.economist.com/news/financeand-economics/21597931-up-point-redistributing-income-fight-inequality-can-liftgrowth-inequality.

Wolf, M. (2014): "Why Inequality Is Such a Drag on Economies," Financial Times. www.ft.com/content/8b41dfc8-47c1-11e4-ac9f-00144feab7de.

Zou, H.-F. (1994): "The Spirit of Capitalism' and Long-Run Growth," European Journal of Political Economy, 10, 279-293.

(1995): "The Spirit of Capitalism and Savings Behavior," Journal of Economic Behavior \&f Organization, 28, 131-143.

(1998): "The Spirit of Capitalism, Social Status, Money, and Accumulation," Journal of Economics, 68, 219-233. 